\title{
Using data to strategically deploy staffing resources
}

\author{
Michael A. Williams \\ Bodleian Libraries, University of Oxford \\ michael.williams@bodleian.ox.ac.uk
}

\begin{abstract}
Purpose: Our environmentally controlled library warehouse stores 10 million collection items and its team of staff provides a delivery service to our students and researchers. Statistics were showing that the demand for the service was much higher than forecast at the design stage and, as a result, the operationally intensive environment had bottlenecks and backlogs which were affecting the service level agreements. It was clear that the staffing levels were inadequate to meet demand so we needed to capture data to enable evidence-based decision making to restructure and supplement staffing.
\end{abstract}

Design, methodology or approach: Each of the activities undertaken by staff was observed and timed over extended periods which resulted in detailed measurements for each elemental task. Based on known demand for services we were able to extrapolate these measurements to model the demand on services and, therefore, the staffing requirement for a whole year.

Findings: We were able to provide evidence to show that the levels of staffing were inadequate and two further full-time equivalent (FTE) staff were required. The data also highlighted specific areas that required higher and lower levels of resourcing than were currently provided.

\section{Legal Deposit storage solution}

The Bodleian Library is the main research library of the University of Oxford and takes its name from Sir Thomas Bodley who re-founded the library within the University in 1602. It is part of the wider University library service, the Bodleian Libraries, which includes major research libraries, libraries attached to faculties, departments and other institutions of the University.

In 1610 Sir Thomas Bodley made an agreement with the Stationers' Company of London under which a copy of every book published in England and registered at Stationers' Hall would be deposited in the new library. This was the precursor to the Legal Deposit Libraries Acts and the Bodleian Libraries remains ones of six Legal Deposit libraries that is entitled to receive a copy of every book published in the UK.

This results in a large intake of printed material which we have to store in perpetuity so our solution is the Book Storage Facility (or BSF) at Swindon, approximately 30 miles (about 50km) from Oxford. Opening in October 2010, it cost £26M to construct and has 153 miles $(246 \mathrm{~km})$ of shelving capable of storing approximately 13 million books. It is designed to store low-use collections including modern collections, rare books, archives, manuscripts, maps and heritage collections including portraits. Up to 7,000 new items are acquired each week. 


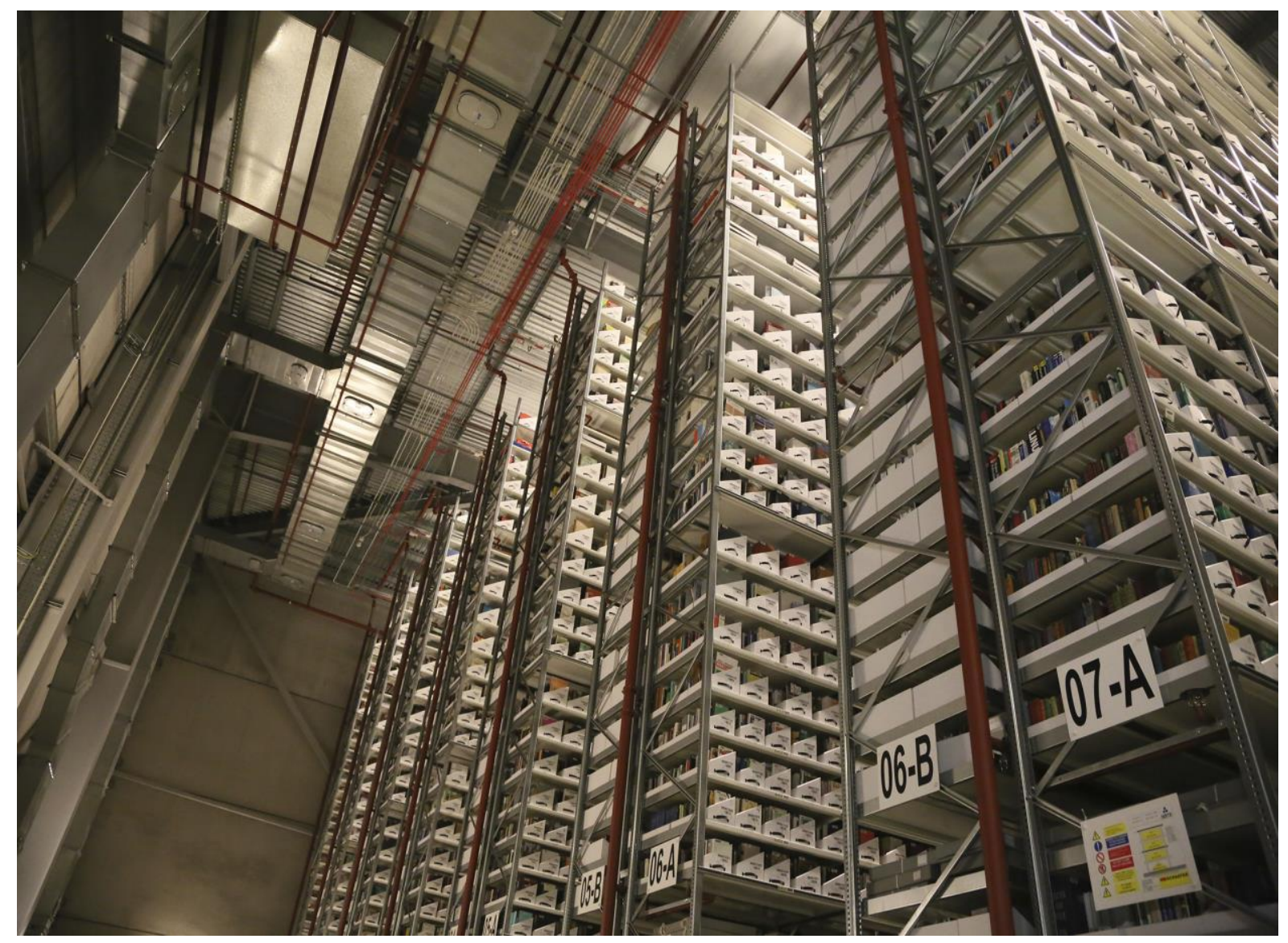

Figure 1. Shelving in the Book Storage Facility

The environmentally controlled library warehouse currently houses 10 million collection items and its team of 15 staff provide a delivery service to students and researchers in 21 libraries across Oxford. Including the management team and project staff there are 22 staff who work at the site.

Increasing demand for collections

At the design phase in 2009, there was an expectation that an increased demand for digital would reduce demand for print resources. Statistics were showing that the demand for the service was much higher than forecast and, as a result, the operationally intensive environment had process inefficiencies which were affecting the service level agreements. Requests placed by users are delivered the same day if placed by 10.30am or the next day if ordered after 10.30am and before 7.30pm. When items are returned, the service level agreement is to reshelve them within 24 hours, thus making them available for requests again. Although it was possible to meet service level agreements for requests, the reshelving of material would often suffer backlogs as the process is much more resource intensive. Library staff, on behalf of users, were requesting items be retrieved from these reshelving backlogs, and this was often a case of looking for the proverbial needle in a haystack.

This was an inefficient use of staffing resources and was having a knock-on effect on other operations.

Around 19,500 items are requested each month and it was clear that the staffing levels were inadequate to meet demand so we needed to capture data to enable evidence-based decision making to restructure and supplement staffing. In reality, digital has complemented print, not replaced it, and access to digital has opened up our collections more widely resulting in a growth in demand in both analogue and digital materials. 


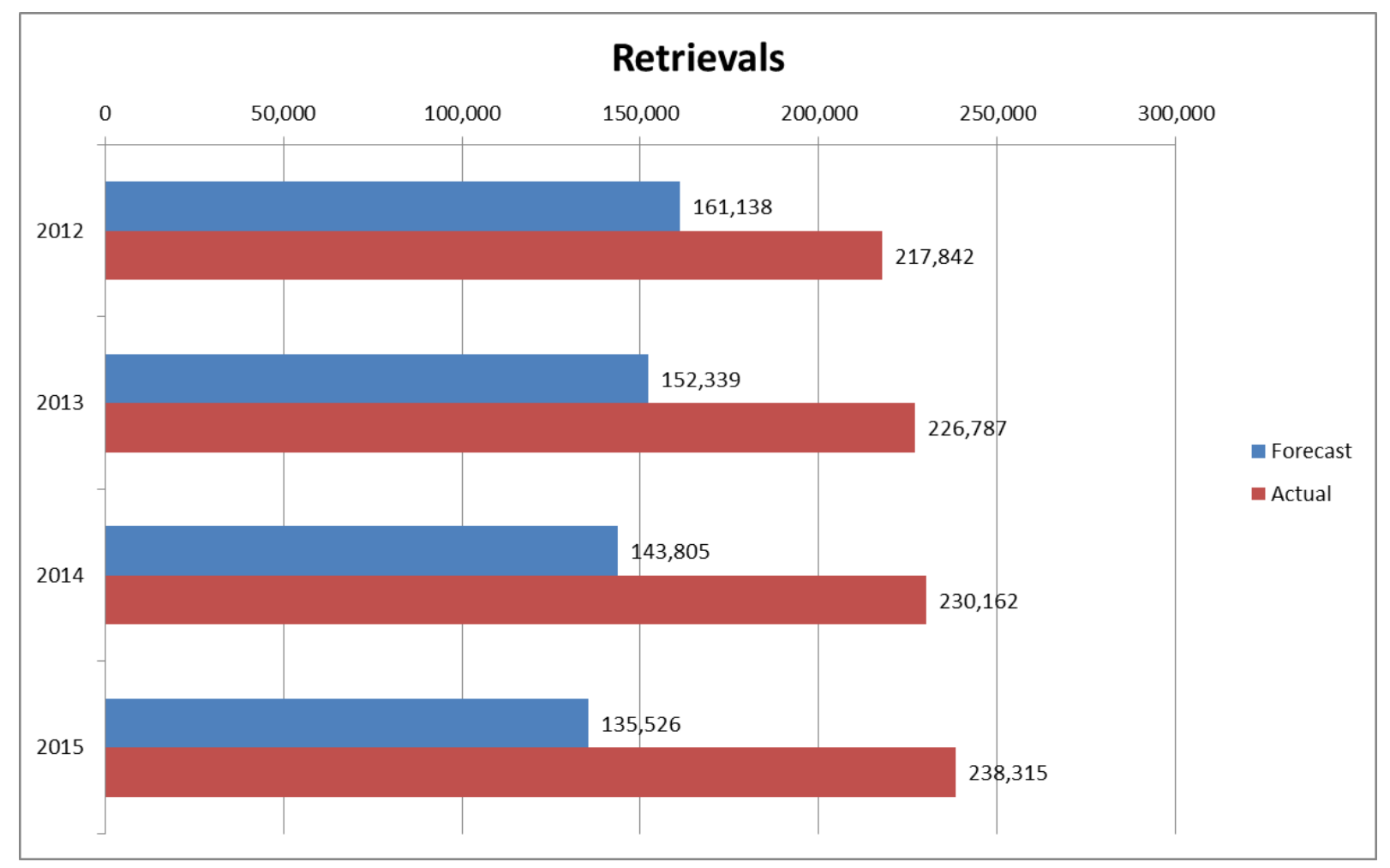

Figure 2. Forecast and actual demand for BSF collections 2012-2015

Figure 2 shows the forecast and actual demand for items stored at the BSF between 2012 and 2015. Each request is known as a 'retrieval'. Rather than decreasing year on year, demand increased significantly and by the end of 2015, the number of items retrieved exceeded the forecast by over 100,000.

To address this growing difference, we were able to adapt the existing staffing to some extent by restructuring and moving vacancies to the areas with the most need. The operations had also bedded in and were able to deliver some process improvements - there is a manager at the warehouse who has this as part of her role. Nonetheless, backlogs and bottlenecks were being created and this had an impact on service levels and our ability to provide access to our collections.

\section{Staffing capacity model}

The solution to this growing problem was to look at all the operational activities underlying the book service and break it down into discrete tasks. Each task was described and measured using a combination of observation and existing performance data and articulated as time taken to complete each task. For example, performance data showed that we are able to retrieve slightly more than one book per minute. The list is exhaustive, right down to allocating time to staff development and training, and resulted in a detailed measurement for each task showing how much time a warehouse assistant spends on each activity (Figure 3). 


\begin{tabular}{|l|l|r|r|}
\hline Work rates & & & \\
\hline Task & Work rate & Minutes & Hours \\
\hline Retrieval & 1.1 books per minute & 0.909 & 0.015 \\
\hline Retrieval verification & 3 books per minute & 0.333 & 0.006 \\
\hline Tote weighing & 850 items per day weighed over 3.5 hours & 0.247 & 0.004 \\
\hline Delivery & 9 hours per day & 540.000 & 9.000 \\
\hline Refile build & 0.65 books per minute & 1.538 & 0.026 \\
\hline Refile & 1.34 books per minute & 0.746 & 0.012 \\
\hline Data download & 60 items in 5 minutes & 0.083 & 0.001 \\
\hline Scan \& Deliver & 10 minutes per scan & 10.000 & 0.167 \\
\hline Maps & 1.3 minutes per map (retrieval and refile) & 0.769 & 0.013 \\
\hline Tray making & 1.5 trays per minute & 0.667 & 0.011 \\
\hline Ingest & 4 books per minute & 0.250 & 0.004 \\
\hline TTS & 1 tray per minute containing 16 items & 0.063 & 0.001 \\
\hline Auditing & 15 minutes per tray (containing 16 items) & 0.938 & 0.016 \\
\hline Cleaning & 60 minutes per day & 60.000 & 1.000 \\
\hline Battery charging & 20 minutes per day & 20.000 & 0.333 \\
\hline Staff development & 1 hour per day (equivalent to 3 days pppy) & 60.000 & 1.000 \\
\hline Travel time & 15 minutes per day & 15.000 & 0.250 \\
\hline
\end{tabular}

Figure 3. Work rates for each operational task

We did explore other methods for measuring capacity, e.g. tracking the lifecycle of requests from fetching, delivery to the libraries and then return to the warehouse but with so many variables and the difficulty in obtaining data for items once they had left the warehouse, this idea was not pursued. We had previously used a model to estimate the cost of delivering items to libraries by tracking the items from the point of fetching from the warehouse shelves through to when they were reshelved. Once items had left the BSF, many people were involved in delivery logistics and customer services to enable the item to reach a user and this varied from library to library (there are 21 different delivery points). What this model showed was that so much of the process was outside of our direct control and was resourced differently in each library so it was not possible to reliably estimate the cost of delivery. We concluded that we should focus on our internal operations for this capacity planning exercise, which we could directly measure and control.

Using the data from previous years, for example the number of retrievals or the number of days in year that a task is undertaken, we can forecast the time required to provide the BSF's services for a whole year. The principal variable is the number of fetches (or "retrievals"). In turn, this dictates the number of items returned ("refiles") and associated tasks. Evidence shows that the number of retrievals in a given year is $2.7 \%$ of the total number of items stored in the warehouse. We knew that around 300,000 items would be removed from the warehouse during the next 12 months to a refurbished library building and this would be partially offset by the number of new items added to the collection. By estimating the total number of items in the warehouse, we can forecast the number of retrievals and other quanta. These figures can then be multiplied by the time taken to do each task to calculate the total staff time needed.

For 2016 the total time required to deliver our services was over 21,000 hours (Figure 4). 


\begin{tabular}{|c|c|c|c|c|c|c|c|}
\hline \multicolumn{8}{|c|}{ Demand on BSF time } \\
\hline & & & & & & & \multirow[b]{2}{*}{ Percent } \\
\hline \multicolumn{2}{|c|}{ Task } & Hours & Unit & Quantum & Unit & Total hours & \\
\hline Retrieval & & \multicolumn{2}{|c|}{0.015 hours/item } & 231,750 & items & 3,511 & $16.5 \%$ \\
\hline \multicolumn{2}{|c|}{ Retrieval verification } & \multirow{2}{*}{\multicolumn{2}{|c|}{$\begin{array}{l}0.006 \text { hours/item } \\
0.004 \text { hours/item }\end{array}$}} & 231,750 & items & 1,288 & $6.0 \%$ \\
\hline \multicolumn{2}{|c|}{ Tote weighing } & & & 231,750 & items & 954 & $4.5 \%$ \\
\hline \multicolumn{2}{|l|}{ Delivery } & \multicolumn{2}{|c|}{9.000 hours/day } & 247 & days & 2,223 & $10.4 \%$ \\
\hline \multicolumn{2}{|l|}{ Refile build } & \multicolumn{2}{|c|}{0.026 hours/item } & 216,300 & items & 5,546 & $26.0 \%$ \\
\hline Refile & & \multicolumn{2}{|c|}{0.012 hours/item } & 216,300 & items & 2,690 & $12.6 \%$ \\
\hline \multicolumn{2}{|c|}{ Data download } & \multicolumn{2}{|c|}{0.001 hours/item } & 216,300 & items & 300 & $1.4 \%$ \\
\hline \multicolumn{2}{|c|}{ Scan \& Deliver } & \multicolumn{2}{|c|}{0.167 hours/item } & 2,000 & items & 333 & $1.6 \%$ \\
\hline Maps & & \multicolumn{2}{|c|}{0.013 hours/item } & 27,802 & items & 356 & $1.7 \%$ \\
\hline \multicolumn{2}{|c|}{ Tray making } & \multicolumn{2}{|c|}{0.011 hours/item } & 15,625 & items & 174 & $0.8 \%$ \\
\hline Ingest & & \multicolumn{2}{|c|}{0.004 hours/item } & 250,000 & items & 1,042 & $4.9 \%$ \\
\hline TTS & & \multicolumn{2}{|c|}{0.001 hours/item } & 250,000 & items & 260 & $1.2 \%$ \\
\hline Auditing & & \multicolumn{2}{|c|}{0.016 hours/item } & 125,000 & items & 1,953 & $9.1 \%$ \\
\hline Cleaning & & \multicolumn{2}{|c|}{1.000 hours/day } & 247 & days & 247 & $1.2 \%$ \\
\hline \multicolumn{2}{|c|}{ Battery charging } & \multicolumn{2}{|c|}{0.333 hours/day } & 247 & days & 82 & $0.4 \%$ \\
\hline \multicolumn{2}{|c|}{ Staff development } & \multicolumn{2}{|c|}{1.000 hours/day } & 247 & days & 323 & $1.5 \%$ \\
\hline \multicolumn{2}{|l|}{ Travel time } & \multicolumn{2}{|c|}{0.250 hours/day } & 247 & days & 62 & $0.3 \%$ \\
\hline Total & & & & & & 21345.7 & $1000 \%$ \\
\hline
\end{tabular}

Figure 4. Forecast demand on staff time for 2016

For the capacity analysis to work we needed to understand how much work an employee could undertake. We calculated the time a member of staff was actually working, taking holidays and sickness into account. Each staff member had a fixed holiday allowance, equating to 265 hours per person. Sickness was calculated by taking an average from the total number of sickness days recorded over the past three years. This average was 68 hours (about 10 days) per person. Across the 13 staff we had working at that time, we had a total capacity of over 18,000 hours (Figure 5).

\begin{tabular}{|l|r|r|r|r|r|r|}
\hline \multicolumn{1}{|l|}{ Available staff time } & & & & \\
\hline & & & & & & \\
\hline & $\begin{array}{r}\text { Working } \\
\text { time }\end{array}$ & $\begin{array}{r}\text { Sickness } \\
\text { time }\end{array}$ & $\begin{array}{r}\text { Holiday } \\
\text { time }\end{array}$ & $\begin{array}{r}\text { Available } \\
\text { time }\end{array}$ & \# staff FTE & $\begin{array}{r}\text { Total } \\
\text { available }\end{array}$ \\
\hline Hours & 1,768 & 68 & 265 & 1,435 & 13 & $\mathbf{1 8 , 6 5 2}$ \\
\hline
\end{tabular}

Figure 5. Available staff time at existing levels of staffing

Using the forecast demand on staff time to provide the BSF's operational services and the number of staff hours available we were able to calculate the staffing capacity for the following year. A simple subtraction showed that we were short of over 2,600 hours, which is the equivalent of almost two people. This was the evidence that demonstrated we had inadequate staffing levels.

We are fortunate that the book service is highly regarded by both readers and the Libraries' Executive as access to the diverse collections stored in the warehouse is key to both the University's teaching and research activities. We were able to put a case together to seek funding for two additional staff members. Using the evidence from our staffing capacity analysis, we were able to convincingly argue for additional staffing at the budget setting round. This was deployed as one full-time staff member and two part-timers. Our experience told us that activity intensity increased in the evenings because the delivery van had completed its two trips, returning material to warehouse which needed reshelving. (It can be seen in figure 
4 that the percentage of time spent on 'refile build' and 'refile' equate to over $38 \%$ of all the activities.) Therefore, two additional, part-time people were required to supplement existing staffing at that time. By presenting the data in this way, showing the shortage of staff time and where it was most needed, we were successful in securing funding for a fixed-term of two years.

With the equivalent of 15 full-time equivalent staff, the available staff time increased to 21,522 hours. This is a level that meets the forecast demand with a surplus of 176 hours across a twelve month period (Figure 6).

\begin{tabular}{|r|r|}
\hline Capacity forecast & \\
\hline Available staff time & 21,522 \\
\hline Demand on BSF time & 21,346 \\
\hline Capacity & 176 hours \\
\hline & \\
\hline Available time & 1,435 per person \\
\hline Staff capacity & $\mathbf{0 . 1}$ \\
\hline
\end{tabular}

Figure 6. Capacity forecast showing the new levels of staffing

The additional staffing enabled us to maintain our service levels in an operationally intensive environment but left flexibility to adapt should the demand for the service change in the future.

\section{Benefits}

With the staffing in place, backlogs and bottlenecks were removed and service levels agreements were met. We also observed some subsequent, unexpected benefits. Staff were able to enjoy greater variety in their work by moving flexibility between all tasks, and the data provide convincing evidence of the team's value which has improved motivation. With empirical data from the modelling, we have been able to provide convincing statistics that drive performance management ensuring individuals are pulling their weight.

\section{Conclusions}

There has long been a perception that digital resources would replace print but the evidence from our book store operations has demonstrated that digital has complemented print, not replaced it. Access to digital has opened up our collections more widely resulting in a growth in demand in both analogue and digital collections.

The research was motivated by operational need in an environment where meeting service level agreements is a key performance indicator. The method can be applied to many library activities and is especially applicable to repetitive or high intensity tasks. It is equally valuable in library operations where there is a perception that staffing levels are inadequate but it is not clear how additional staffing should be deployed. 